\title{
RELAÇÃO ESCOLA, EDUCAÇÃO E A LUTA DE CLASSES E SEUS PAPEIS NA FORMAÇÃO DO SUJEITO REVOLUCIONÁRIO
}

\author{
RELACIÓN ESCUELA, EDUCACIÓN Y LA LUCHA DE CLASES Y SUS PAPELES EN LA \\ FORMACIÓN DEL SUJETO REVOLUCIONARIO
}

\section{SCHOOL, EDUCATION AND CLASS STRUGGLE RELATIONSHIP AND THEIR ROLE IN THE FORMATION OF THE REVOLUTIONARY SUBJECT}

DOI: http://dx.doi.org/10.9771/gmed.v11i1.26786

\author{
Breno Pascal de Lacerda Brito ${ }^{1}$ \\ Victor Montalvão Moreno 2 \\ Thayse Ancilla Maria de Melo Gomes ${ }^{3}$
}

Resumo: O atual ensaio tem como objetivo tratar o papel que a escola exerce na formação ideológica das pessoas e da necessidade da construção do sujeito político. Para tal será discutido o posicionamento da escola e a conformação dos meios educacionais, o papel da Pedagogia Histórico-Crítica, e elementos que podem contribuir para a construção de uma formação revolucionária.

Palavras-chave: Escola; conformação social; educação crítica; papel social.

Abstract: The present essay aims to deal with the role that the school plays in the ideological formation of the people and the necessity of the construction of the political subject. For that will be discussed the positioning of the school and the conformation of the educational means, the role of Historical-Critical Pedagogy, and possibilities that can contribute to build a revolutionary formation.

Keywords: School, social conformation, critic education, social role.

Resumen: El presente ensayo tiene como objetivo tratar sobre el papel que la escuela ejerce en la formación ideologíca de las personas y de la necesidad de la construcción de un sujeto político. Para esto se discute la posición de la escuela y la conformación de los medios educativos, y el papel de la pedagogía histórico-crítica; y las posibilidades que pueden contribuir pala la construción de una formación revolucionaria.

Palabras Clave: Esculea, conformción social, educación erítica, papel coial

\section{Introdução}

Segundo Ponce (1981), o ensino possui uma relação considerável com a estrutura da sociedade, sendo utilizado, geralmente, como uma ferramenta para a construção de uma conformação perante o padrão social existente. Essa relação pode ser traduzida, de forma simplificada, no papel que a sociedade espera que uma pessoa possa exercer após passar pelo processo escolar (PONCE, 1981).

Ao analisar a sociedade contextualizada pela luta de classes, percebe-se uma diferenciação nesses papéis com base na classe pertencente, na qual a formação do trabalhador é direcionada às classes exploradas, enquanto nas classes dos exploradores os sujeitos são estimulados a ocupar a direção e os cargos mais elevados (PARO, 1999). Assim, entre um dos papéis que a escola desempenha, e que este 
texto explora, a escola assume uma função de formar pessoas de acordo com as classes sociais as quais elas são originárias, fazendo uma manutenção da ideologia da classe dominante (LUCKESI, 2012).

De acordo com Gramsci (1982), a função reservada à escola, mas não somente a ela, reforça uma formação social que influencia na construção da identidade de classe e, consequentemente, na concepção social que eles possam vir a ter e a defender. Como resultado desse processo, tal formação reforça um tipo de resposta dos alunos que tende a ser reacionária e não revolucionária, no sentido de proporcionar condições para que os estudantes possam refletir sobre seu contexto e alterá-lo significativamente (LOUREIRO, 2005; SOCIETY, 2010).

Por isso, a organização tradicional das escolas e a formação científica dos alunos tendem a atuar influenciando uma construção intelectual dos jovens e sua atuação coletiva reforçando os papeis esperados da sua classe social (PONCE, 1981; TONET, 2012). Ou seja, a escola formal tem edificado um ser humano conservador (PARO, 1999) e dificilmente proporciona elementos para a construção de um sujeito emancipador (LOUREIRO, 2005).

Nesse sentindo, Chang (2013) salienta que a formação de um sujeito crítico não perpassa pela reprodução do conhecimento científico tradicional que geralmente as escolas brasileiras abordam, já que o ensino não pauta e nem se propõe a fornecer as ferramentas básicas para o processo de emancipação humana (CHANG, 2013).

A ausência da escola na formação de agentes emancipadores pode ser observada em países que são considerados "exemplos" em suas políticas educacionais como a Finlândia, Japão, Canadá e Coreia do Sul que, apesar de seus costumeiramente elogiados sistemas educacionais, mantêm não só o caráter explorador do Estado Burguês, como o enrijecimento da estrutura de classe e da sociedade capitalista.

Desse modo, problematizamos o caráter que a escola tradicional vem desenvolvendo nessa atuação, principalmente por não fornecer subsídios para a construção de sujeitos críticos que possam avaliar adequadamente sua realidade e intervir nela. Portanto, colocamos em relevo que esta composição apenas favorece uma parcela pequena da sociedade, as classes dominantes, e não a sua grande maioria que é composta por trabalhadores e trabalhadores e que não conseguem, através da educação formal, impulsionar uma real ascensão de vida pautada em uma lógica mais humana e igualitária caminhando na contra mão da composição atual da sociedade, o capitalismo.

Com base nisso o presente ensaio aponta que da mesma maneira que a escola atualmente defenda o interesse da minoria dominante, ela pode vir a defender e a colaborar com a maioria desprivilegiada, uma vez que ela é uma instituição mutável, com potencial revolucionário. Todavia, esta mudança só é possível a partir de movimentos de resistência e disputa.

Nessa direção, vislumbrando discutir os elementos apresentados, o presente artigo se dividirá em dois momentos, o primeiro focado na relação da escola e do ensino na formação ideológica do sujeito e como ela pode ser em prol de uma nova ideologia focada na formação do indivíduo mais crítico e dono do seu próprio destino. E no segundo momento apresentaremos qual base pedagógica contribui mais efetivamente para a formação desse sujeito de inclinação revolucionária e sua importância no processo de emancipação. 


\section{Papeis da escola - da situação a subversão}

Conforme Ponce (1981), a escola nos moldes contemporâneos é uma invenção moderna, que surge na 1a República Francesa, possuindo como principal objetivo a formação de uma massa letrada, laica e apta aos mecanismos laborais necessários à manutenção da nova ordem estabelecida. Para Boto (2003), essa nova escola tinha em um dos seus principais objetivos a formação ideológica de um ideário coletivo atrelado a necessidade da conformação de uma concepção de um sujeito político, agora não mais atrelado às obrigações monárquicas e sim aos ideais republicanos e a ordem burguesa ascendente. A nova formação era pautada então, nos princípios da Revolução de 1789, cortando os laços ideológicos do Ancien Régime e dando o lastro e a manutenção necessária ao avanço das conquistas da revolução (BOTO, 2003).

Todavia, essa nova escola, por mais que apresentasse a tentativa de pela primeira vez ter uma concepção de universalidade da formação básica (BOTO, 2003), ainda estava atrelada a tradição dos liceus de ensino e antigas academias para educar a elite de forma diferenciada das classes subalternas e com objetivos distintos (PONCE, 1981), mantendo, paralelamente, a lógica de formação da mão de obra necessária aos interesses da burguesia (SAVIANI, 2011).

Ou seja, a escola, no processo de passagem do conhecimento técnico, também apresentava as bases da nova ideologia dominante, que apenas as favoreciam, e as normas necessárias para a manutenção da mesma. Nesse processo a educação formal se torna uma educação mantenedora do status quo. Isso se dá pela percepção dos riscos associados pela elite dessa formação emancipadora das classes exploradas, mantendo sempre uma balança daquilo que deve ser formado para garantir a qualidade do profissional, mas sem colocar em risco a posição dos exploradores enquanto classes superiores (SILVA, 2011; TONET, 2012).

Como dito anteriormente, essa posição da escola funciona como um guia a dois caminhos, não só a formação técnica necessária para o trabalho alienado, mas também a formação ideológica que impede mudanças drásticas na lógica do novo Estado Burguês (POUNCI, 1981; TONET, 2006). Esse caráter da educação científica e o posicionamento escolar foram cada vez se definindo mais dessa maneira no passo que o Estado Burguês se consolidava e a burguesia deixava de ser uma classe revolucionária para se tornar uma classe contrarrevolucionária.

Por isso, a educação se torna uma forma de controle social de alto sucesso, principalmente durante o séc. XX (LUCKESI, 2012). Através dela se têm então não só uma concepção de como a sociedade deve existir, mas principalmente de quais as formas de analisá-la e quais os pontos que devemos lutar para melhorá-la. A sociedade então deixa de buscar uma emancipação e o fim das classes para adotar um discurso reformista, pautado na liberdade individual e na paz entre as classes (TONET, 2008).

Nesse processo as reformas do ensino e a subversão da escola à lógica do liberalismo tiveram um grande peso (PARO, 1999; TONET, 2012). Peso não só na consolidação do Estado Burguês, como da introdução de narrativas no ideário das classes subalternas da inviabilidade revolucionária, do fim da história (TONET, 2008) e da descaracterização do trabalho enquanto fundante do ser social (DUARTE, 2000). 
Dessa forma, a educação e a escola tradicional se tornaram agentes da alienação do trabalho, retirando a autonomia e controle do trabalho pelo trabalhador, impossibilitando, por esse caminho, que trabalhadores fossem donos de seu próprio destino, ou que estes atuassem de modo igualitário com os donos do Capital (SILVA, 2011). É valido notar que essa perda da autonomia do sujeito poderia acentuar o caráter do conflito de classe, porém o discurso ideológico da formação cidadã, ou mesmo a maquiagem humanitária dos novos processos educacionais e administrações escolares apenas afastam as classes trabalhadoras de uma capacidade de se enxergar enquanto classe e da importância do trabalho para a sua transformação e para a transformação da sociedade (ENRIQUEZ, 1999).

Essa questão não só já era debatida por Marx e Engels (SILDA, 2012; PIRES, 1997), como também foi vista como fundamental para a criação de uma nova sociedade durante os processos revolucionários do socialismo real. Havia o reconhecimento da criação de um novo sujeito político (SERNA; ROIO, 2006) e se tinha a escola e o processo educacional como grandes mecanismos da criação desse novo sujeito e consequentemente dessa nova sociedade (DAVYDOV, 1995).

Essa necessidade de um novo sujeito então municia a escola de uma responsabilidade maior no que tange a emancipação do indivíduo. Primeiro devemos entender que a emancipação não irá acontecer de forma indolor ou mesmo de forma repentina. Ela será alcançada através da luta de classes e do acirramento da mesma, forçando assim as classes subalternas a se levantarem e se tornarem emancipadoras no processo de luta (MARX, 1998).

E é nesse ponto que a escola deve ser capaz de atuar e o processo educacional tem que ser pensado (MAYO, 2010), ou seja, em capacitar as classes exploradas a protagonizarem sua luta e serem capazes de se tornarem dona de sua própria história. Devemos nos atentar que, apesar da importância da escola e das etapas educacionais nesse processo, não cabe apenas a ela a responsabilidade de guiar o processo revolucionário e sim de equipar seus participantes do conhecimento e habilidades necessárias para um maior aproveitamento do processo de emancipação que a classe se encontrará quando assumir o caráter revolucionário da luta de classes (TONET, 2012).

A escola então deve agir como uma zona de enfrentamento à ideologia burguesa hegemônica e o processo de ensino pensado de forma a apresentar e formar uma nova ideologia entre os membros da classe proletária (FERNÁNDEZ, 1977). Essa nova ideologia deve ser focada na formação coletiva do indivíduo, no seu domínio do trabalho para sua própria transformação e do meio em que vive. Esse direcionamento da formação do sujeito coletivista e emancipado politicamente, reforçaria então o enfrentamento às classes da elite e a mudança do processo de dominação de uma classe por outra (SMET, 2014).

É importante salientar aqui o papel que a passagem do conhecimento científico tem nesse processo. Essa educação formal das classes explorada não só tem uma forte visão do papel do conhecimento científico no aprimoramento da capacidade de transformar o meio e a si próprio (ENRIQUEZ, 1999; TONET, 2008), como tem um papel na própria formação ideológica dessas classes. Ao se apropriar do conhecimento humano mais avançado, as classes subalternas reforçam a ideia delas 
serem possuidoras daquilo que é gerado coletivamente e assim melhor se capacitam de derrubar as amarras ideológicas que as prendem ao status quo hegemônico (SAVIANI, 2013).

Outro papel desse aprendizado é a superação da ideia da diferença associada aos tipos de saberes e da superioridade daqueles que geram trabalho intelectual (geralmente associado às classes da elite, hoje principalmente a burguesia e os seus associados diretos) sobre os geradores do trabalho material (ROIO, 2006). Essa superação é essencial para o entendimento dialético material do mundo e assim sua maior capacidade de modificá-lo e de se apropriar das ferramentas da luta de classes e da emancipação humana (MARX, 1998).

A importância da escola no papel transformador da realidade dos estudantes de classes exploradas por vezes é reconhecida pelos próprios estudantes, que são capazes de assumir posições revolucionárias diante de desmandes autoritários do status quo. É o que nos mostram as jornadas de mobilização estudantil em São Paulo, Brasil, entre outubro e dezembro de 2015. Elas foram motivadas pelo remanejamento do ensino público estadual paulista, que propunha "disponibilizar" 94 escolas que, fechadas, deixariam de atender a rede estadual, o que impactaria num rearranjo de outras 1.464 unidades e 311 mil alunos sendo obrigados a mudar de escola (PINHO, 2015).

Inspirados no manual chileno "Como Ocupar Uma Escola" que foi traduzido por um coletivo e amplamente divulgado, os estudantes chegaram a ocupar 213 escolas (RBA, 2015). Com grande apoio popular às ocupações, o governador de São Paulo demitiu o então secretário de educação e suspendeu o plano de reorganização (G1, 2015). O impacto das ocupações foi nacional, inspirando outros movimentos semelhantes em outros estados (PIOLLI, 2016), o que pode ser interpretado como um indicativo de como o corpo estudantil, quando alimentado sua consciência política, pode agir como uma força motriz de movimentos emancipatórios, principalmente em contextos de acirramento da luta de classes marcado com a austeridade contra as classes exploradas.

As ocupações contradisseram a suposição de que devido a precariedade do ensino público os estudantes encontravam-se alienados à dinâmica política escolar (MORAES, 2016), demonstrando como o acirramento da luta de classes estimula o levante das classes exploradas. Como produto, temos um movimento social autônomo, cujas características podemos salientar: independência, horizontalidade, autogestão e utilização de táticas de desobediência civil e de ação direta (PIOLLI, 2016). É crasso apontar que estas características usualmente estão presentes em outros movimentos de carácter revolucionário/emancipatório e formação de consciência de classe como os levantes anti-imperialistas ou mesmo nos movimentos revolucionários. Entretanto, as ocupações se destacam pelo caráter espontaneista e autonomista (MORAES, 2016), pois apesar da apropriação das próprias forças de formação pela classe trabalhadora frente as investidas do Capital, as ocupações não se mostraram organizadas politicamente para uma resistência e formação continuada.

Podemos concluir o raciocínio então que a escola pode exercer um papel crítico para a formalização da ideologia de uma classe emancipadora e do fornecimento das ferramentas científicas que possam possibilitar um entendimento mais concreto do funcionamento do mundo e como intervir no mesmo (DUARTE, 2008; 2015). Essa visão é reforçada pela capacidade que escolas em países socialistas 
apresentam de formação politica juntamente com a científica, mantendo os ideais revolucionários vivos, como por exemplo as escolas cubanas (BLUM, 2011) Entretanto, o que observamos é uma educação meramente técnica para formação de uma classe explorada em constante processo de alienação com os produtos oriundos do seu conhecimento e do seu trabalho pois tem como objetivo final apenas a inserção no mercado de trabalho (GOMES et al., 2018). Essa contradição não é nem de longe pacífica, tendo em vista os movimentos citados de enfrentamento a esta lógica opressora que surgiram dentro do corpo escolar e espalharam-se pelo país. Devemos tratar agora de como se deve dar o processo de ensino para garantir a formação dessa classe de forma a contribuir substancialmente para este enfrentamento.

\section{A pedagogia histórico-critica e a formação da classe trabalhadora}

A função da escola tem que estar associada com uma estratégia pedagógica específica para que se possa cumprir seu papel na formação de uma classe que assume para si a função de emancipar a humanidade das amarras do Estado Burguês. Essa metodologia deve então seguir a lógica de ser socialmente pautada, dado que a formação dessa classe deve ser associada dialeticamente à sua própria realidade e a concepção do aprendizado social e coletivo do homem.

Devido a essa necessidade, podemos perceber o papel que a pedagogia histórico-critica (PHC) pode desempenhar na formação desse sujeito político. A PHC tem em sua base o materialismo-dialético, ou seja, a consideração das contradições da formação do ser social e do aprendizado científico, além de estar intimamente vinculada ao contexto de armar a classe trabalhadora de ferramentas que lhe permitam sua emancipação. Por isso, é capaz não apenas de municiar o trabalhador com possíveis ferramentas para superar os vícios ideológicos capitalistas na sociedade de luta de classes (SAVIANI, 2013), como ter um papel na formação do novo sujeito revolucionário (BARROCO, 2007).

A PHC baseia seu projeto na transformação psicológica e educacional através das demandas sociais não pautadas nos interesses do Capital, se propondo a situar os processos educacionais com base nas necessidades e relações sociais que o indivíduo tenha e que o circunde, principalmente ao levar em consideração as consequências da sociedade pautada no conflito de classes e a formação da psique humana nesse processo (MARTINS, 2012). Ao considerar esse movimento da formação do indivíduo e garantir que essa formação se dê através de processos de situações de intervenções coletivas e situando o conhecimento de forma prática (DUARTE, 2000), a formação escolar através da PHC pode ser lida como uma tática que tenha como objetivo a formação de um novo sujeito político, que seja capaz de mostrar autonomia intelectual pautada em uma formação de cunho popular e emancipador (DAVYDOV, 1995).

Por isso, analisando a necessidade da educação de sujeitos revolucionários, a PHC apresenta então uma base consistente para tal empreitada. Isso se dá pela preocupação da formação do sujeito para um fim objetivo (no caso a emancipação social da classe trabalhadora) com base na análise dialética do método marxista, que é a base epistêmica da PHC, seja em Vigostly, Galperin ou Leontiev (NÚÑEZ, 2009). Esse método garante que o sujeito seja capaz de articular conceitos científicos no entendimento de 
dada situação, além de conseguir projetar a importância das relações sociais tanto para análises mais acuradas dos eventos objetivos, como no próprio processo educacional.

Nesse sentido a PHC pode contribuir para a transformação de um movimento com caráter meramente reformista para uma perspectiva mais revolucionária, compreendendo que problemas e questões pontuais por vezes são meras reverberações dos conflitos de uma sociedade de classes. Retornemos ao exemplo das ocupações estudantis paulistas. Muito embora tenham servido de inspiração e modelo de organização política para outras ocupações com diferentes pautas (PIOLLI, 2016), é pungente como o foco recaia sobre pautas específicas de um contexto local, embora aquecidas por incômodos generalizados com o sistema público de ensino. Não à toa o atendimento dessas pautas por parte do governo levava a desocupação das escolas e retorno ao modelo antigo de gestão verticalizada com baixa ou nenhuma participação estudantil. Esse "hiato participativo" estabelece a falta de capilaridade dos movimentos políticos: como sua estrutura hierárquica e cristalizada tem encontrado dificuldade de estabelecer diálogos com sua base (BASILIO, 2017), demonstrando a dificuldade que existe em sensibilizar a juventude da importância de enxergar a sociedade de uma perspectiva marxista. Aqui podemos considerar, de forma teórica, que um dos motivos dessa pouca resistência permanente do movimento estudantil que coordenou as ocupações, seja consequência da não elaboração de uma formação crítica com o foco na formação de um sujeito revolucionário, apto a entender sua condição concreta e atuar para modificá-la. Ao adotar do autonomismo e de pedagogias usualmente pós-modernas, pouco se fez para a formação de resistência real dos participantes do movimento.

Como Saviani (2013) defende, a PHC é capaz de preparar o trabalhador então à entender o conjunto de contradições e complexidades que fazem parte da luta de classes e como a classe burguesa se mobiliza através do uso de recursos ideológicos e legais ${ }^{1}$ para poder dissociar e impedir a classe trabalhadora do reconhecimento e protagonismo em seu papel revolucionário. Bem como é capaz de formar os membros das classes exploradas a se mobilizarem através de um objetivo em comum e articular seus saberes em prol desse objetivo e melhor articular as necessidades objetivas que podem transformá-las (as classes exploradas) em classes em processo emancipatório (SMET, 2014).

É esse processo que se deve buscar alcançar, e garantir que uma vez em movimento não se desvie do caminho em meio a atitudes contrarrevolucionárias ou reacionárias articuladas pelas classe burguesa, principalmente por vias que esmorecem a luta ao alcançar objetivos táticos, esquecendo a estratégia de fundo e se contentando com um reformismo leve, como vemos comumente em movimentos de luta pontuais.

Para tal, se torna necessário formar uma cultura de resistência e de identidade política pautada na justa causa dos interesses das classes subalternas de emancipar a humanidade (MAYO, 2010; ROIO, 2006). O interesse da classe trabalhadora deve ser garantido através de sua formação política bem definida,

\footnotetext{
1. Por recursos ideológicos entendemos o uso dos meios discursivos e culturais que desmobilizam as classes exploradas da luta revolucionária ou a impedem da criação da consciência de classe necessária para sua emancipação, já recursos legais entendemos como o uso do aparato repressivo do Estado Burguês com a finalidade de enfrentar as manifestações das classes exploradas, salvaguardando os interesses do Capital
} 
e como dito anteriormente o primeiro momento dessa formação é justamente associado a formação formal e ideológica da classe trabalhadora em meio aos processos escolares. A concepção que esses processos estão associados a outros processos sociais, que refletem o conflito de interesses das classes, é essencial para a formação protagonista do curso da história que a classe trabalhadora deve assumir. E é, mais uma vez, nesse aspecto que a PHC é capaz de fornecer as ferramentas pedagógicas necessárias (PIRES, 1997).

\section{Conclusão}

Há uma necessidade cada vez maior de se formar o sujeito político para além do individualismo da sociedade liberal burguesa (TONET, 2008). Uma formação coletivista, pautada na identidade de classe e na concepção clara do valor do trabalho e de sua importância na formação do sujeito e da humanidade, é um dos principais fatores para se vencer a ideologia individualista e alienante da atualidade. Como defendido, preliminarmente, nesse breve ensaio, para entender melhor o processo de formação desse novo indivíduo político revolucionário, devemos focar nossas análises nas contradições dos processos escolares e quais as ferramentas pedagógicas devemos utilizar para uma formação em direção a esse indivíduo revolucionário.

Dessa forma a escola pode agir enquanto uma força subversiva contra a ordem burguesa, atuação que pode ser estimulado com uma pedagogia focada nas necessidades da classe proletária em meio a luta de classes. Tal atuação pode trazer benefícios táticos na atual situação política de acirramento da luta de classes, advindo das crises cíclicas do capitalismo especulativo, e com possíveis resultados exitosos.

Essa atenção do papel da escola enquanto local de formação científica e política se faz necessária principalmente no atual ciclo de ofensiva neoliberal no Brasil, que busca atacar não só os direitos dos trabalhadores, como também a própria capacidade da escola atuar enquanto local de formação científica básica. Essa nova condição da luta de classes no país, o qual tem uma de suas frentes justamente o ensino e a conformação das escolas, nos mostra a necessidade de reconhecer as escolas como local de importante fonte de análise para entender o processo das contradições da formação política. Juntamente com as Ocupações de 2015, podemos reconhecer o potencial de enfrentamento que as escolas e seus estudantes podem exercer e assim utilizar desse potencial para além de entender a formação políticas dos sujeitos, estimular que essa formação seja em direção a formação de sujeitos revolucionários.

Concluímos esse breve ensaio, pontuando que não se esgota a questão da relação entre a escola a educação e a luta de classes, porém apontamos as questões preliminares de suma importância a entender essa questão.

\section{Referências bibliográficas}

BARROCO, Sônia. A Educação especial do novo homem soviético e a psicologia de L.S. Vigotsky: Implicações e contribuições para a psicologia e a educação atuais. Universidade Estadual Paulista Julio de Mesquita Filho, Araraquara, 2007. 
BASILIO, Ana. Um ano pós-ocupações: avançamos com a participação juvenil? Carta Educação. 2017. Disponível em http://www.cartaeducacao.com.br/reportagens/um-ano-pos-ocupacoes-avancamos-comparticipacao-juvenil/. Acessado 11/05/2018.

Blum, 2011. Cuban Youth and Revolutionary Values: Educating the New Socialist Citizen. University of Texas Press, 2011

BOTO, Carlota. Na revolução francesa, os princípios democráticos da escola pública, laica e gratuita: o relatório de Condorcet. Educação \& Sociedade, v. 24, p. 735-762, 2003.

CHANG, Ha-Joon. Mais instrução por si só não tornará um país mais rico. In: 23 coisas que não nos Contaram sobre o Capitalismo. São Paulo: Cutrix, 2013.

DAVYDOV, Vasily. The Influence of L. S. Vygotsky on Education Theory, Research, and Practice. Educational researcher, v. 24, p. 12-21, 1995.

DUARTE, Newton. A anatomia do homem é a chave da anatomia do macaco: a dialética em Vigotski e em Marx e a questão do saber objetivo na educação escolar. Educação \& sociedade, v. 21, p. 79-115, 2000.

ENRIQUEZ, Eugène. Perda do trabalho, perda da Identidade. Relações de Trabalho Contemporâneas, p. 69-83, 1999.

FERNÁNDEZ, Francisco. Actualidad del pensamiento político de Gramsci. Barcelona: Ediciones Grijalbo, 1977.

G1 São Paulo. Alckmin suspende reorganização da rede de ensino estadual de SP. G1, 04/12/2015 12h17

- Atualizado em 04/12/2015 17h14. Disponível em: <http://g1.globo.com/sao-paulo/escolasocupadas/noticia/2015/12/alckmin-suspende-reorganizacao-da-rede-de-ensino-estadual-de-sp.html>.

Acessado 11/05/2018.

GOMES, M. A. de O., FERRAZZO, G., \& LÔBO, C. B. A Educação escolar e formação para o Mercado: A "empregabiliade" e a produção do Trabalho Precarizado. Germinal: Marxismo e Educação em Debate, v 10, n 2 p.48-57, 2018.

LOUREIRO, Carlos. Práxis política e emancipatória em educação. Educação e sociedade, v. 26, p. 1473-1494, 2005.

LUCKESI, Cipriano. Tendências Pedagógicas na prática escolar. 2012.

MARTINS, Lígia. O desenvolvimento do psiquismo e a educação escolar: contribuições à luz da psicologia histórico-cultural e da pedagogia histórico-crítica. Comunicação saúde educação, v. 16, p.283, 2012.

MARX, Karl; ENGELS, Freidrich. The German ideology: including Theses on Feuerbach and introduction to The critique of political economy. Great Books in Philosophy, 1998.

MAYO, Peter. Gramsci and educational thought. West Sussex: Wiley-Blackwell: 2010.

MORAES, Carmen; XIMENES, Salomão. Políticas educacionais e a resistência estudantil. Educação \& sociedade, v. 37, p. 1079-1087, 2016.

NÚÑEZ, Isauro Béltran. Vigotsky, Leontiev e Galperin: formação de conceitos e princípios didáticos. Brasília. Liber Livro. 215pp. 2009.

PARO, Vitor. Parem de preparar para o trabalho!!! Reflexões acerca dos efeitos do neoliberalismo sobre a gestão e o papel da escola básica. 1999.

PINHO, Márcio. Reorganização atinge 311 mil alunos e 'disponibiliza' 94 escolas de SP. 2015. Disponível em: < http://g1.globo.com/sao-paulo/noticia/2015/10/reorganizacao-escolar-em-sp-tem-94escolas-que-serao-disponibilizadas.html>. Acessado 11/05/2018.

PIOLLI, Evaldo; PEREIRA, Luciano; MESKO, Andressa. A proposta de reorganização escolar do governo paulista e o movimento estudantil secundarista. Crítica educativa, v. 2, p. 21-35, 2016.

PIRES, Marília. O Materialismo histórico-dialético e a educação. Interface - Comunicação, saúde, 
educação, v. 1, p 83-94, 1997.

PONCE, Anibal. Educação e luta de classes. São Paulo: Cortez, 1981.

Redação RBA. Ocupação contra projeto de Alckmin já chega a 213 escolas. 2015. Disponível em: <http://www.redebrasilatual.com.br/educacao/2015/12/mesmo-com-repressao-policial-ocupacao-jachega-a-213-escolas-estaduais-6247.html>. Acessado 11/05/2018.

ROIO, Marcos. Gramsci e a educação do educador. Cad. Cedes, v. 26, p. 311-328, 2006.

SAVIANI, Dermeval. A pedagogia histórico-crítica, as lutas de classe e a educação escolar. Germinal: Marxismo e educação em debate, v. 5, p. 25-46, 2013.

SAVIANI, Nereide. Escola e luta de classes na concepção marxista de educação. Germinal: Marxismo e educação em debate, v. 3, p. 7-14, 2011.

SERNA, Ernesto. O Socialismo e o Homem em Cuba. Disponível em: $<$ https://files.comunidades.net/cicero-negocios/O_Socialismo_e_o_homem_em_Cuba.pdf $>$. Acesso em: 10/05/2018.

SILVA, João. A questão educacional em Marx: Alguns apontamentos. Germinal: Marxismo e educação em debateminal, v. 3, p. 72-81, 2011.

SMET, Brecht. A Dialectical Pedagogy of Revolt: Gramsci, Vygotsky and the Egyptian Revolution. Boston: Brill, 2014.

SOCIETY, I. Focus on private schooling in china the reemergence of private schools in socialist China. Comparative Education, v. 41, p. 244-259, 2010.

TONET, Ivo. Educação e formação humana. Ideação, v. 8, n. 9, p. 09-21, 2006

TONET, Ivo. Educação contra o Capital. São Paulo: Instituto Lukács, 2012.

TONET, Ivo; LESSA, Sérgio. Introdução à filosofia de Marx. São Paulo: Expessão popular, 2008.

\footnotetext{
Notas:

${ }^{1}$ Laboratório de Ensino, Filosofia e História da Biologia (LEHFBio) - Universidade Federal da Bahia. ORCID: http://orcid.org/0000-0001-88453941 Email: brenoplbrito@yahoo.com.br

${ }^{2}$ Laboratório de Ensino, Filosofia e História da Biologia (LEHFBio) - Universidade Federal da Bahia. ORCID: Email: legrandemonta@gmail.com

${ }^{3}$ Coletivo de Estudos em Marxismo e Educação (Colemarx) - Universidade Federal do Rio de Janeiro. ORCID: http://orcid.org/0000-00016592-4755 Email: thaymelog@gmail.com
} 